\section{Cureus}

Received 10/16/2016

Review began 12/21/2016

Review ended 01/08/2017

Published 01/13/2017

\section{(c) Copyright 2017}

Kadhem et al. This is an open access article distributed under the terms of the Creative Commons Attribution License CC-BY 3.0., which permits unrestricted use, distribution, and reproduction in any medium, provided the original author and source are credited.

\title{
Spontaneous Unilateral Adrenal Hemorrhage in Pregnancy
}

\author{
Salam Kadhem ${ }^{1}$, Rawaa Ebrahem ${ }^{1}$, Cyrus M. Munguti ${ }^{1}$, Rami Mortada ${ }^{2}$ \\ 1. Internal Medicine, University of Kansas School of Medicine - Wichita 2. Endocrinology, University of \\ Kansas School of Medicine - Wichita
}

$\square$ Corresponding author: Salam Kadhem, skadhem@kumc.edu

Disclosures can be found in Additional Information at the end of the article

\section{Abstract}

Spontaneous adrenal hemorrhage (SAH) is a serious medical condition associated with variable clinical presentation depending on the extent of the hemorrhage. Pregnancy-induced adrenal hemorrhage is poorly understood. A low cortisol level in the peripartum period with radiological findings is sufficient to establish the diagnosis. Prompt hormone replacement and supportive care to ensure good clinical outcomes is crucial. Due to the potentially lifethreatening complications, physicians should have a high suspicion for adrenal hemorrhage when they evaluate patients with hypotension, fatigue, and abdominal pain during the peripartum period.

Categories: Endocrinology/Diabetes/Metabolism, Internal Medicine, Obstetrics/Gynecology Keywords: spontaneous unilateral adrenal hemorrhage, pregnancy, spontaneous recovery

\section{Introduction}

Abdominal pain is a common symptom in pregnancy and rarely is adrenal hemorrhage high on the list of differential diagnoses. Spontaneous adrenal hemorrhage (SAH) is an uncommon condition that if misdiagnosed can lead to adrenal crises [1]. SAH can occur in the absence of trauma or during the use of anticoagulants. The incidence of SAH ranges from $0.14 \%$ to $1.1 \%$, and it usually involves the right gland [2]. The incidence during pregnancy is unknown [3]. While some patients with adrenal hemorrhage may be asymptomatic, the common presentation includes nonspecific pain located in the epigastrium, flank, upper or lower back, or pelvis in 65-85\% of cases [2]. Symptoms of adrenal insufficiency, such as fatigue, weakness, dizziness, anorexia, nausea, vomiting, myalgia, and diarrhea, are present in approximately $50 \%$ of extensive, bilateral adrenal hemorrhage cases [1].

The most common causes of unilateral adrenal hemorrhage are blunt abdominal trauma, primary adrenal tumors, or metastatic tumors. Uncomplicated pregnancy infrequently has been associated with spontaneous unilateral adrenal hemorrhage [2]. We present a case of spontaneous unilateral adrenal hemorrhage occurring during pregnancy that was discovered after delivery and managed conservatively. Informed consent was obtained from the patient for this study.

\section{Case Presentation}

A 35-year-old female at 36 weeks of gestation presented with a one-week history of left flank pain, nausea, vomiting, and fatigue. She denied fever, urinary frequency, and urgency. The pain was sharp, constant, non-radiating, and gradually getting worse. She had been having this pain 


\section{Cureus}

since the 24th week of gestation and had gone to the ER twice for the same reason. She had two previous uneventful pregnancies and no significant medical or surgical history. An examination revealed normal vital signs, a normal sized fundal height for gestation, and mild tenderness on the left renal angle.

The urinalysis, complete blood count, and comprehensive metabolic panel were nonsignificant. An abdominal ultrasound was suspicious for adrenal bleed. She had a normal vaginal delivery on the second day of her hospitalization but continued to have left flank pain, as well as nausea, emotional lability, fatigue, and general malaise. A postpartum abdominal computed tomography (CT) scan revealed left adrenal hemorrhage (Figures 1-2).

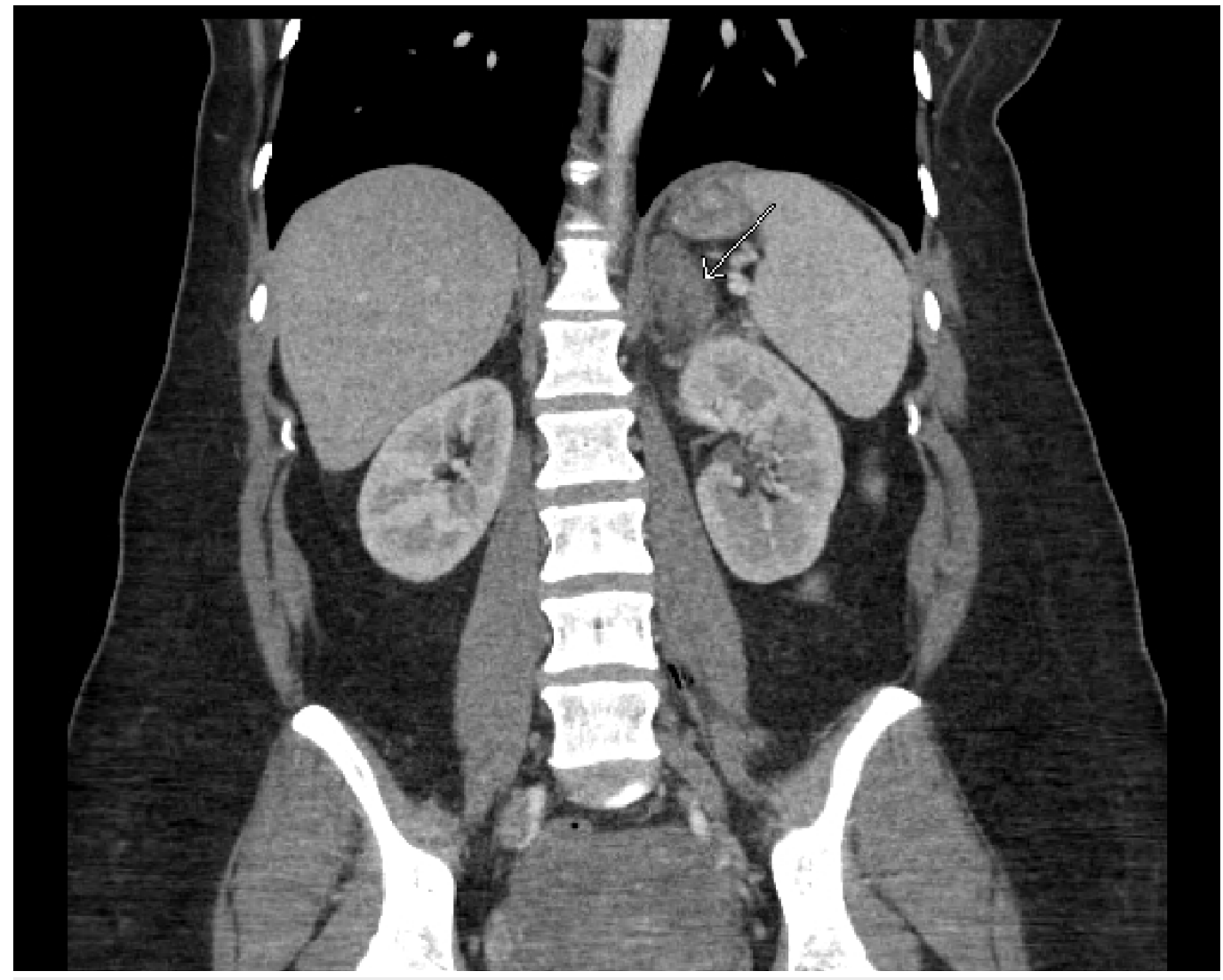

FIGURE 1: Sagittal CT scan image demonstrates left adrenal hyperattenuation (arrow) consistent with adrenal hemorrhage 


\section{Cureus}

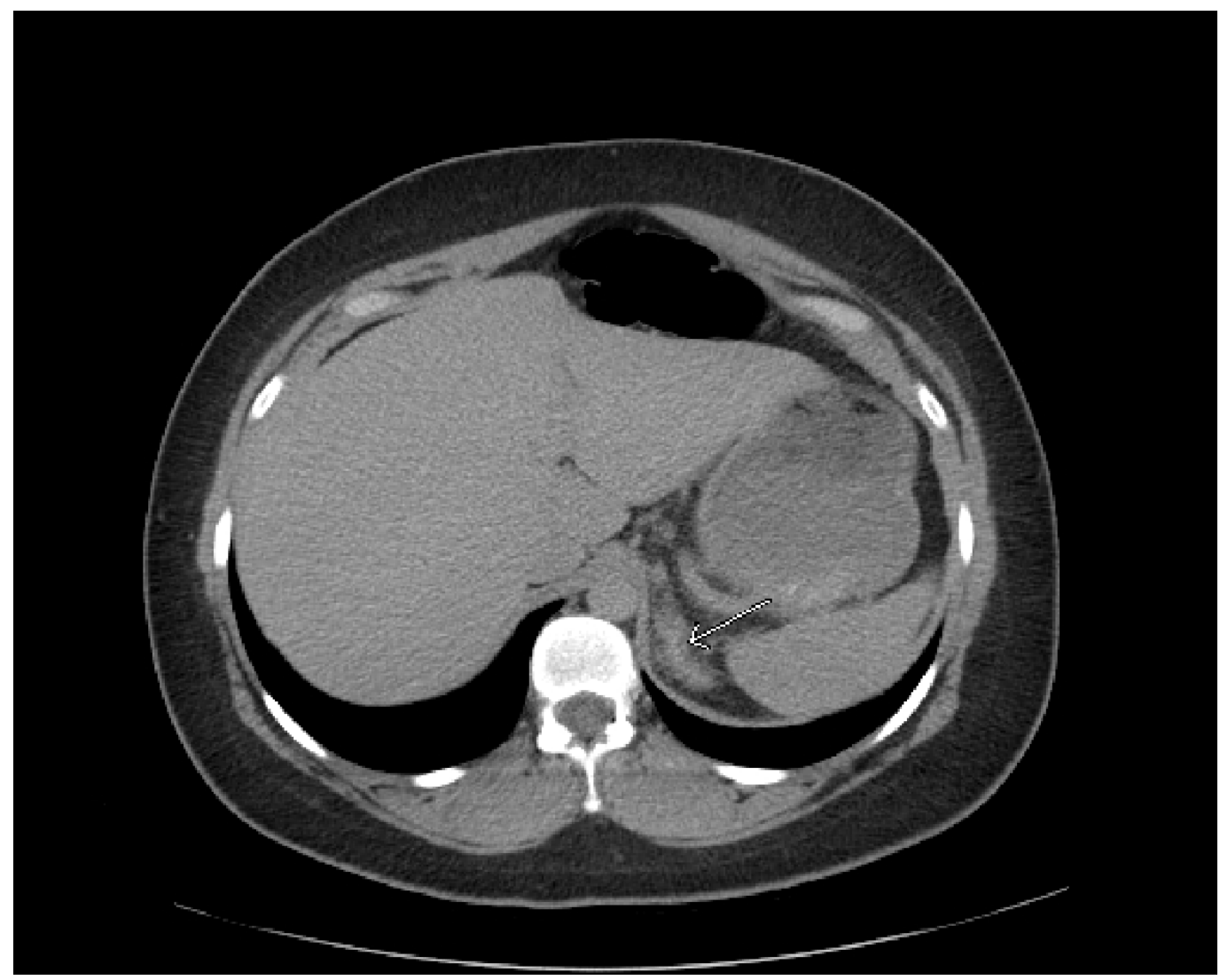

FIGURE 2: Cross-sectional abdominal CT scan with hyperattenuation of the left adrenal gland consistent with
adrenal hemorrhage (arrow)

Morning cortisol was low at $3.4 \mathrm{mcg} / \mathrm{dl}$. She was started on oral hydrocortisone for spontaneous left adrenal hemorrhage, and her symptoms improved dramatically. She was discharged on oral steroids, and, during outpatient follow-up with endocrinology, she had no complaints, and her cortisol and adrenocorticotropic hormone (ACTH) levels were normal. A repeated CT scan of the abdomen showed resolving hematoma, and the steroid dose was tapered gradually and eventually stopped 15 months later.

\section{Discussion}

Adrenal hemorrhage is an uncommon condition with a variable presentation that, if not recognized immediately and treated appropriately, may lead to acute adrenal crisis, shock, and death. The underlying mechanism of adrenal hemorrhage in non-traumatic cases is unclear; the available evidence has implicated ACTH, adrenal vein thrombosis, and spasm [4].

Adrenal hemorrhage can occur in pregnancy without apparent cause; however, adrenal hyperplasia during pregnancy increases arterial blood supply. Limited venous drainage might be a risk factor [5], and other differentials to be considered in pregnancy include pregnancy toxemia, twisted ovarian cyst, abortion, and postpartum hemorrhage.

Common presentations of adrenal hemorrhage include abdominal pain, tenderness, fever, hypotension, and shock, if not treated appropriately. Therefore, as previously mentioned, a high suspicion for adrenal hemorrhage with a low threshold for the diagnosis is crucial. Ultrasound is the first diagnostic choice during pregnancy, while MRI would be a highly 
sensitive as well as specific modality to rule out serious underlying causes like pheochromocytoma and adenoma [6].

Conservative management with fluid resuscitation, steroid therapy, and correction of underlying coagulopathies are necessary. Surgery is indicated for the patients who are not responding to conservative management and continue to deteriorate despite aggressive resuscitation. Adrenal insufficiency should be addressed to prevent circulatory collapse [7]. In severe hemorrhage, arterial embolization may be needed as a bridging for subsequent surgery [8]. Full recovery of adrenal function is expected following resorption of the hematoma, with discontinuation of steroid therapy [9].

\section{Conclusions}

Non-traumatic adrenal hemorrhage is a rare but serious complication during pregnancy. Physicians should be aware of it and have a high suspicion and low threshold for this diagnosis due to the high mortality rate associated with improper treatment. Clinicians need to be aware of the variable presentations of SAH and prompt initiation of appropriate care. Steroid replacement is the key to a successful outcome.

\section{Additional Information}

\section{Disclosures}

Human subjects: Consent was obtained by all participants in this study. Conflicts of interest: In compliance with the ICMJE uniform disclosure form, all authors declare the following: Payment/services info: All authors have declared that no financial support was received from any organization for the submitted work. Financial relationships: All authors have declared that they have no financial relationships at present or within the previous three years with any organizations that might have an interest in the submitted work. Other relationships: All authors have declared that there are no other relationships or activities that could appear to have influenced the submitted work.

\section{References}

1. Wani MS, Naikoo ZA, Malik MA, et al.: Spontaneous adrenal hemorrhage during pregnancy: review of literature and case report of successful conservative management. J Turk Ger gynecol assoc. 2011, 12: 263-5. 10.5152/jtgga.2011.61

2. Imga $\mathrm{N}$, Tutuncu $\mathrm{Y}$, Tuna $\mathrm{M}$, et al.: Idiopathic spontaneous adrenal hemorrhage in the third trimester of pregnancy. Case Rep Med. 2013, 2013: 10.1155/2013/912494

3. Gavrilova-Jordan L, Edmister WB, Farrell MA, et al.: Spontaneous adrenal hemorrhage during pregnancy: a review of the literature and a case report of successful conservative management. Obstet Gynecol Surv. 2005, 60:191-195.

4. Kovacs KA, Lam YM, Pater JL, et al.: Bilateral massive adrenal hemorrhage. Assessment of putative risk factors by case controlled method. Medicine. 2001, 80:45-53.

5. Vella A, Nippoldt TB, Morris JC 3rd, et al.: Adrenal hemorrhage: a 25-year experience at the Mayo Clinic. Mayo Clin Proc. 2001, 76:161-168. 10.1016/S0025-6196(11)63123-6

6. Shantha N, Granger K: Spontaneous adrenal haemorrhage in early pregnancy . J Obstet Gynaecol. 2008, 28:449-451. 10.1080/01443610802141316

7. Bockorny B, Posteraro A, Bilgrami S: Bilateral spontaneous adrenal hemorrhage during pregnancy. Obstet Gynecol. 2012, 120:377-381. 10.1097/AOG.0b013e31825f20a7

8. Patel A, Downing R, Vijay S: Spontaneous rupture of the adrenal artery successfully treated using the endovascular approach: a report of 2 cases. Vasc Endovascular Surg. 2013, 47:124127. 10.1177/1538574412469284

9. Shen JZ, Stranks SN, Ho JT: Spontaneous adrenal haemorrhage in pregnancy . Intern Med J. 2011, 41:362-363. 10.1111/j.1445-5994.2011.02453.x 